\title{
IMPLEMENTATION OF COGNITIVE BEHAVIORAL THERAPY (CBT) FOR THE ELDERLY IN REDUCING ANXIETY DUE TO LANDSLIDES IN MARGAMUKTI VILLAGE-BANDUNG REGENCY
}

\author{
Tukino \\ Bandung Polytechnic of Social Welfare \\ tukinoktn@gmail.com
}

\begin{abstract}
This study aims to reveal the application of Cognitive Behavioral Therapy (CBT) in reducing anxiety experienced by elderly victims of landslides disaster in Margamukti Village, Pangalengan District, Bandung Regency. Specifically, this is to determine: 1) the anxiety experienced by the client "Iy" after the landslide disaster, 2) the application of CBT in reducing anxiety experienced by "Iy" clients. This study uses a quantitative approach with a single subject design (SSD). The data collection technique is done through questionnaires in the form of Hamilton Rating Scale for Anxiety (HRS-A), interviews, and observations. Analysis of research data using quantitative measurement techniques. The results showed that the application of CBT to the respondent "Iy" resulted in a better change, namely a decrease in anxiety, although the changes resulting from the series of interventions carried out by the researcher were not too large, meaning that the respondent "Iy" still experienced a feeling of disturbance in the "moderate" category. During the measurement process of both the baseline phase A and baseline phase B, and the measurement of phase A2 from the aspect of the relationship that is built between the researcher and the respondent "Iy", the process is quite meaningful, namely the relationship that builds respondent "Iy" growth towards psychosocial recovery.
\end{abstract}

Keywords:

elderly, disaster, cognitive behavioral therapy 


\section{INTRODUCTION}

On May 5, 2015 there was a landslide disaster in Cibitung-Margamukti Village, Pangalengan District, Bandung Regency, which resulted in casualties and property damage in the form of heavily damaged, moderate and lightly damaged houses, 54 families displaced, 10 people injured, 7 victims died and 3 people have not been found until now (BNPB: 2015). One of the survivors of the disaster is Mr. "Iy", an elderly person who now lives in RT 05 RW 02, Margamukti Village.

Based on the results of an exploratory study, respondents "I" now live their daily lives feeling uncertain as victims of landslides. Physically he suffered severe injuries, namely on his back and his left hand was difficult to move, while his right hand had tremors. Psychologically, respondent "Iy" feels helpless because he can't work, the trauma of the accident that happened to him, and feels anxious about his family life. Respondent "Iy" lives with a wife, two children and two grandchildren. Anxiety is a response from various aspects to the treatment of situations, characterized by cognitive fear, arousing neuropsychological, and subjective experiences of tension. Humans experience anxiety for a variety of reasons, but factor analysis of anxiety suggests solutions that include at least interpersonal anxiety (Robinson, P. John: 1991).

The purpose of this study was to determine the level of anxiety experienced by respondents "Iy" after landslides, and the application of cognitive behavioral therapy in reducing "Iy" anxiety in Margamukti VillagePangalengan, Bandung Regency. The reason that strengthens the conduct of this study is based on the belief that the aspect of anxiety is one of the elements in the biopsychosocial of the elderly in everyday life after landslides, considering that social work practices are directed at increasing the biopsychosocial of the elderly itself.

A social worker who works with the elderly who are victims of a disaster, must have the skills to help people make obvious (visible) behavior changes, and use cognitive techniques to change the cognitive distortions of people's self-destructive beliefs. Cognitive theory suggests that behavior is influenced by perceptions or interpretations of the environment during the learning process. Improper behavior usually arises as a result of misperceptions and misunderstandings (Beck, 1989 and Ellis, 1962).

\section{METHOD}

This study uses a quantitative approach with a single subject design (SSD), which is a research design to evaluate the effect of a treatment with a single case or subject (Kazdin, in Latipun, 2011: 85). In this case the researcher uses a cognitive behavioral therapy (CBT) techniques. The CBT design used is A $\mathrm{B}-\mathrm{A}$, which is a design that shows a causal relationship between the independent and dependent variables. At first the target behavior is continuously measured at the baseline condition (A1) with a certain time period, then at the intervention condition (B), and the second baseline condition (A2) or outcome.

The research data were collected using a questionnaires in the form of Hamilton Rating Scale for Anxiety (HRS-A) with 14 question items. The degree of anxiety are as follows:

score <14: None

score 14-20: Light

score 21-27: Moderate

score> 27: Heavy

Apart from using the instrument, indepth interviews were also carried out to "Iy" and his family, and observations which took 
place during the process of implementing A-BA.

Data analysis used quantitative measurements, with the following stages: 1) scoring the results of the baseline condition assessment 1,2) scoring the results of the intervention condition assessment, 3) making an assessment table for the scores that have been obtained in the baseline and intervention conditions, 4) comparing the results scores on baseline and intervention conditions, 5) making data analysis in the form of line graphs, so that the differences can be seen, 6) making conclusions on the results of data analysis.

\section{RESULT}

\section{Characteristics of Respondents}

The respondent of this research is a male aged 70 years (elderly), with the initials "Iy", is Muslim, and has a junior high school education. Respondent "Iy" has one wife, one daughter who is married, and two grandchildren. His entire family lives in RT 03 RW 2 Margamukti Village. As a survivor of the landslide disaster in Cibitung Village that occurred in early May 2015, respondent "Iy" now lives his daily life by mostly staying at home.

Before the landslide disaster occurred, respondent "Iy" worked as a farmer working on a plantation owned by PTPN Malabar, where the local residents allowed the plantation area to work on. As a farmer working on the land owned by PTPN Malabar, he and his wife and children have worked on the land for years as their daily livelihood

When the landslide disaster occurred on May 5, 2015, several hours earlier the respondent "Iy" and his wife were on the plantation land where they cultivated the land with palawija plants, as well as freshwater fish cultivation. At around 14:50, suddenly there was a very loud explosion in the plantation area in the Cibitung area, on that day there was a landslide disaster. Landslides hit pipes belonging to PT. Star Energy, a natural gas management company. The large pipes flew along with the landslide and hit several people's houses. The landslide hit respondent "Iy", which resulted in "Iy" being heavily injured in the back, upper legs and arms. The landslide disaster resulted in the respondent "Iy" and his wife suffering serious injuries, as well as losing the plantation land that he was working on because it was destroyed by landslides. Then he underwent medical treatment, psychologically, respondent "Iy" still felt traumatized by the landslide incident, and felt helpless because he could not work to support his family. Respondent "Iy" said that his property had been sold out for the medical expenses he was undergoing, which cost him around 45 million rupiah for treatment.

\section{Baseline phase A (measurement of anxiety level before intervention)}

1) Measurement session I

Researchers collected baseline data before the intervention which aims to measure the level of anxiety of respondents "Iy" after landslides using an instrument in the form of the Hamilton Rating Scale for Anxiety (HRSA). Measurements were made on July 7, 2017. The measurement results showed that the respondent "Iy" got a score 24, meaning that the anxiety is in the moderat category. This is shown in the aspect of anxiety namely; feeling tense, irritable, easily startled, shaking (tremors), muscle twitching, restless, afraid of crowds and crowds, waking up at night, sleeping poorly, nightmare, feeling weak, and losing weight.

\section{2) Measurement session II}

At the next meeting on July 14, 2017, the researcher returned to the respondent's house to collect baseline data for the second time, using 
the same instrument in session I. The measurement results showed the respondent "Iy" got a score of 22, which means that the respondent's level of anxiety was still in the category "moderat". However. respondent "Iy" stated that he is better able to talk to other people and is less irritated.

\section{3) Measurement session III}

At the next meeting on July 21, 2017, the researcher returned to the respondent's house to collect baseline data for the third time, using the same instrument in sessions I and II. The measurement results show the respondent "Iy" gets a score of 21. This means that the respondent's level of anxiety has decreased but is still in the "moderate" category. Respondent "Iy" stated that he is now calmer and less restless.

Table 1. Baseline measurement results (A1) anxiety level respondent "Iy"

\begin{tabular}{lll}
\hline No & Measurement session & Score \\
\hline$\overline{2}^{1}$ & Session I & \\
3 & Session II & 24 \\
& Session III & 21 \\
\hline
\end{tabular}

\section{Baseline phase B (application of CBT techniques)}

In this section, researchers designed a baseline application with the target of reducing post-landslide anxiety in "Iy" respondents through the application of Cognitive Behavioral Therapy (CBT). CBT focuses on helping "Iy" respondents make obvious (visible) behavior changes, and integrates using cognitive techniques to change cognitive distortions of self-destructive beliefs. The implementation of CBT for respondents "Iy" which took place from 12, 19, 20, and 26
August 2017, was carried out by applying the following techniques:

\section{a. Coping skill}

This technique is used to initiate the intervention stage, which is to create a psychological reaction in the form of anxiety that arises in the respondent "Iy" that this is normal. In this case the researcher as well as the therapist is a friend to listen to what "Iy" says. The application of coping skills to respondent "Iy", namely:

1) Researchers try to understand the situation and provide support to respondent "Iy" with respect for their dignity and self-worth. At the earliest opportunity of this intervention, the approach to psychological pain victims and trauma counseling should be postponed immediately.

2) Encourage "Iy" respondents to adjust to feelings of loss, namely property due to landslides that have occurred, and changes in living conditions. On this occasion the researcher did not act directly to provide suggestions, but instead let the respondent "Iy" get their own answers to the problems they were experiencing.

\section{b. Problem Solving}

This technique emphasizes human life as a process of solving life's problems, the client makes and chooses solutions by acting the best for him and reviewing his progress. This is one of the techniques in emotional stabilization, namely the ability to maintain and restore the basic functions of a person experiencing anxiety, with an orientation to balance physical disorders such as a pounding heart, feeling tired, back pain, avoidance behavior, shaken behavior because of the problems it faces as a result, affected by landslides, and feel worried about his life and feel helpless.

The steps for applying problem solving techniques are: 
1) Researchers as a therapist try to understand the physical conditions experienced by respondents "Iy", both their health conditions and the fulfillment of daily physical needs. In this case the researchers reaffirmed the data obtained from the respondent "Iy" that physically they often experience back pain, trembling hands, decreased energy, sometimes headaches, and increased blood pressure.

2) The researcher tries to arouse the willingness and ability of the respondent "Iy" so that he can recover from his physical illness immediately by going to the doctor at the local Puskesmas.

3) Developing the capacity of the respondent "Iy" to be able to maintain their own health so that they do not continue to experience the same disease.

\section{c. Cognitive Restructuring}

1) Rational Emotive Behavior Therapy (REBT)

The application of the REBT technique is based on the observations of the researcher that the respondent "Iy" still has negative thoughts about his current living conditions after the landslide that occurred, that is, he still blames the village government for not paying attention to the problems it faces. The objectives to be achieved by applying this REBT technique are; reduce cognitive anxiety disorders that exist in respondent "Iy", and help develop the abilities they still have. The application of the REBT technique was carried out in 4 meetings, namely from 2 to 5 August 2017. The place used was the residence of the respondent "Iy". The steps for implementing the REBT technique are as follows:

a) The stage of building a close relationship (Rapport)

The good relationship between the researcher and the respondent "Iy" has been built since the beginning of the meeting and the baseline intervention phase B of the first session. However, to improve a more intimate relationship, the researcher tries to create a rapport, by developing empathy, positive regard, developing a friendly attitude towards the researcher (personal warmth), and sincerity in relationships.

b) Cognitive stage (management of thoughts and views)

This stage consequently the role of the researcher is to identify, explain and show the problems $(\mathrm{ABC})$ faced by respondents "Iy" with their irrational beliefs, teach and provide information (about ABC theory), discuss problems (indicate the direction of change, from irrational belief to rational belief. to be achieved in counseling.

c) Emotive and affective management stage

The researcher focuses on the emotion or affection of the respondent "Iy" as a supporting condition for the stability of changing irrational belief to rational belief. In this stage, the researcher: asks the respondent for full agreement on the direction of the changes that have occurred, maintains an atmosphere of intervention with the rapport that has been built, and relaxes.

d) The behavior management stage

In this case, if the respondent has signaled that he: agrees on the direction of change, and there is a statement that there have been a number of changes in negative thinking to positive thinking, emotional attitudes are faced with behavior changes, then the researcher is ready to enter the behavior management stage.

2) Cognitive structural therapy

This technique is related to the belief structure that is in the mind of the respondent "Iy", namely the core beliefs which are assumptions about oneself. On this occasion 
the researcher focuses on the outermost beliefs that cause problems in respondent "Iy", but uses a change process to explore the origin of these beliefs in deeper thinking. In this case the researcher:

a) Encouragement, motivating respondents "Iy" to behave as desired

b) Formation, namely the formation and strengthening of small steps towards the desired behavior

Graph 1. Level of anxiety of respondent "Iy" after implemented intervention

Level of anxiety after intervention baseline (B)

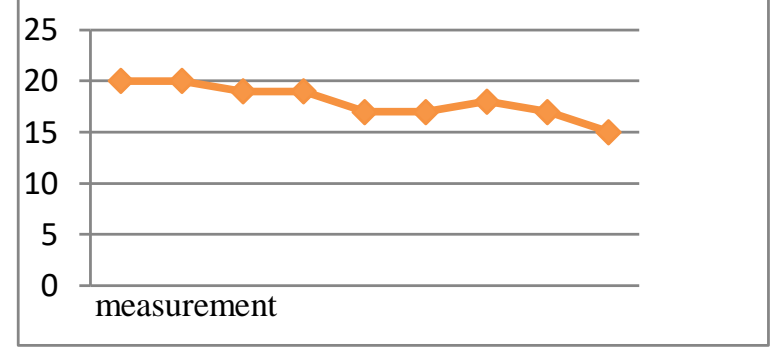

Based on graph 1 it explains that the anxiety level respondent's "Iy" in the baseline phase B experienced several changes in anxiety levels. It can be seen that there are certain times that show an increase in anxiety levels and a decrease in anxiety levels, even though the respondent's level of anxiety "Iy" is in the moderate category.

\section{Baseline phase A2 (measurement of anxiety level after intervention)}

Based on the results of the implementation of the baseline intervention stage (B), the results of measuring the level of anxiety in phase A2, the respondent "Iy" obtained a score of 19, meaning that the level of anxiety is in the "mild" category. The following graph 2 shows the development of anxiety of respondent "Iy".
Graph 2. The results of the intervention on anxiety of respondents' "Iy"

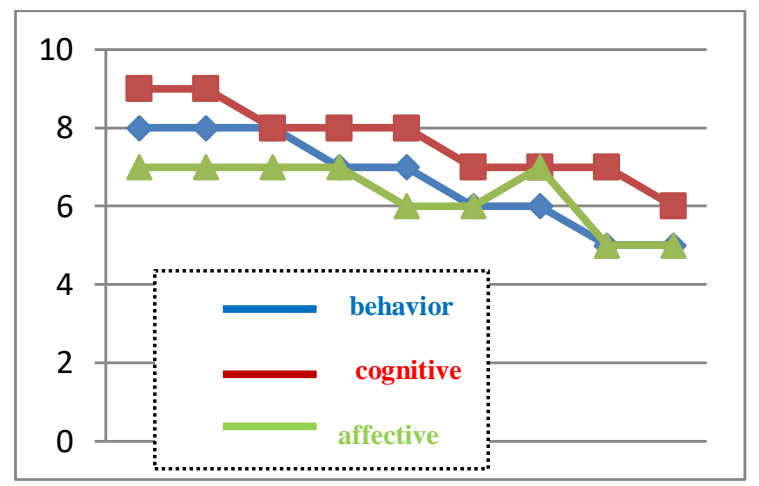

Behaviorally, the respondent "Iy" no longer feels pain in his back and trembling in his hands, only occasionally feels that, as well as the energy that becomes the spirit of his life in carrying out his daily routine. At the time of baseline A measurement session III, respondent "Iy" sometimes likes to avoid events that involve many people, such as community meetings, but after several meetings with researchers at baseline $B$, respondent "Iy" stated that he did not feel ashamed and returned with other community members. to be directly involved in community activities.

Cognitive aspects, when compared with the baseline measurement results of A1 session III where respondents "Iy" still often feel confused about their present life and the future of their family life after landslides, after intervening through various techniques, feelings of confusion do not often arise, negative thinking only appears every now and then, and the last chance the researcher met the respondent "Iy", he seemed to be more enthusiastic about living his daily life.

Affective aspects; Respondents still feel anxious about their life now because the gardening land where they work was hit by landslides, and PTPN Malabar has not been 
allowed to be used by the activity community again.

\section{DISCUSSION}

This study aims to determine the application of cognitive behavioral therapy (CBT) in the elderly to reduce anxiety due to landslides. In this study, there were three main stages, namely the stage before the implementation of the intervention (baseline pahse A1), the intervention stage (baseline stage B) and the stage after the intervention (baseline stage A2).

The results showed that at the baseline phase A1, the measurement of respondents' anxiety "Iy" which is based on behavioral, cognitive, and affective anxiety is in the moderate category, however, the measurement of session I, session II and session III shows a decreasing score, namely session I got a score of 24, session II with a score of 22 , and in session III it fell by a score of 21 . The decrease in the score on the measurement before the intervention was carried out can be understood as the result of the communication process between the researcher and the respondent "Iy", namely communication that raises awareness or even healed in some parts of respondent "Iy" anxiety, especially in the cognitive aspect by changing the respondent "Iy" way of thinking about the problems they face, as well as in the affactive aspect where feelings of anxiety, tension, and worry in respondent "Iy" are slowly experiencing change to a more positive direction.

Furthermore, at the baseline phase B, researchers used coping skill techniques, problem solving, and cognitive restructuring by applying rational emotive behavior therapy (REBT) and cognitive structural therapy. All of these techniques are steps in operating cognitive behavioral therapy (CBT). CBT is the systematic application of techniques derived from the principles of learning (conditioning and social learning theory) to help people behave in an adaptive manner. In the context of this research, the expected behavior change in respondent "Iy" is a decrease in anxiety behavior, and an effect on cognitive and affective changes.

In the measurement after the intervention (baseline phase A2), the respondent's anxiety level fell to a score of 19, which means that the anxiety was in the "mild" category. This shows that the application of CBT to respondents "Iy" is quite effective, that is, it results in changes in behavioral, cognitive and affective aspects, although the changes achieved do not eliminate anxiety in respondents "Iy". The economic aspects that are not carried out in the application of CBT could be another determinant factor that causes anxiety to the respondent "Iy" that it has not disappeared or healed, considering that at the time of this study the respondent "Iy" had not yet obtained a replacement job from agricultural land which could no longer be used because hit by a landslide disaster.

\section{CONCLUSION}

The life of the elderly after a landslide disaster is faced with changes in behavior, thoughts and affections that will affect the conditions of anxiety in living their daily lives. This study generally aims to determine the application of cognitive behavioral therapy (CBT) to reduce the level of anxiety of respondents "Iy".

The research problem solving proposed by the A-B-A model has a causal relationship. The baseline results of A - B - A indicate that the application of Cognitive Behavioral Teraphy (CBT) to respondents "Iy" resulted in a change for the better, namely a decrease in anxiety from moderate to mild levels, although 
the changes achieved resulted in the series of interventions that the researcher did not to eliminate the overall anxiety in the respondent "Iy. However, in the measurement process of both the baseline phase A and baseline phase B, and the measurement phase $A 2$, the communication process that is built between the researcher and the respondent becomes a separate space to foster the confidence of respondent "Iy" to lead a more meaningful life.

\section{REFERENCES}

Beck, Judith S. 2011. Cognitive-Behavior Therapy: Basic and Beyond (second edition). New York: The Guilford Press

Burn, David D. 1988. Terapi Kognitif: Pendekatan Baru bagi Penanganan Depressi. Jakarta: Erlangga

Cooper, M.G. \& Lesser, J.G. (2005). Clinical social work practice: An integrated approach ( $2^{\text {nd }}$ edition). Boston: Pearson Education, Inc.

Corcoran, J. \& Walsh, J. (2004). Clinical assessment and diagnosis in clinical social work practice. New York: Oxford University Press.

Juang Sunanto (2006). Penelitian dengan Subjek Tunggal. Bandung: UPI Press

Nurul Mawaddah, Aman Wijayanto (2020). Peningkatan Kemandirian Lansia Melalui activity Daily Living Training dengan Pendekatan komunikasi Terapeutikdi Rsj Dr. Radjiman Wediodiningrat Lawang (Jurnal: Hospital Majaphit, Vol 12 No.1 Februari 2020). Diakses dari http://ejournal.stikesmajapahit.ac.id/index. $\mathrm{php} / \mathrm{HM} / \mathrm{article} / \mathrm{view} / 491$

Maguire, L. (2002). Clinical social work: Beyond generalist practice with individuals, groups, and families. Pacific Grove, CA: Brooks/Cole
Payne, M (2016). Teori Pekerjaan Sosial Modern (F.Nugroho \& M.S. Nainggolan, Eds.4 th). Yogyakarta: Samudera Biru

Robinson, P. John, et-al. 1991. Measures of Personality and Social Psychological Attitudes. San Diego : Academic Press Limited

Sheafor, B.W. \& Horejsi, C.R. 2003. Tachniques and Guidelinea for Social Work Practice. Boston: Allyn and Bacon.

Stuart, G.W and Laraia, M.T. (2005).

Principles and Practice of Psychiatry Nursing. (3th ed). Philadelphia: F.A Davis Company. Available from https://books.google.co.id/books?id=ivAL BAAAQBAJ

Yuhansyah Nurfauzi, Djoko Wahyono. Et al. (2020). Creative communication in networking services as the social skill of geriatric pharmacist (International Journal of Research in Pharmaceutical Sciences). Available from https://pharmascope.org/ijrps/article/view/1 917

Yung-Chin Tsao, Chun-Chieh Shu, and TianSyung Lan (2019). Development of a Reminiscence Therapy System for the Elderly Using the Integration of Virtual Reality and Augmented Reality. Taiwan: Tatung University, Taipei City 10491. Available from: https://econpapers.repec.org/article/gamjsu sta/v_3a11_3ay_3a2019_3ai_3a17_3ap_3a 4792-_3ad_3a263403.htm 